Annals of International Medical and Dental Research

E-ISSN: 2395-2822 | P-ISSN: 2395-2814

Vol-8, Issue-1 | January-February 2022

DOI: 10.53339/aimdr.2022.8.1.13

Page no- 93-97 | Section- Research Article (Physiology)

\title{
Anxiety and Depression in School-going children with Epilepsy
}

\author{
Linus Francis ${ }^{1 *}$, Davis Manuel²
}

1Department of Psychiatry, P K Das Institute of Medical Sciences, Vaniamkulam, Palakkad, India, Email: cozimlinu@hotmail.com Orcid ID: 0000-0002-0687-8987

2Department of Pediatrics, P K Das Institute of Medical Sciences, Vaniamkulam, Palakkad, India. Email: davismanuel@gmail.com

Orcid ID: 0000-0002-5553-235X

${ }^{*}$ Corresponding author

Received: 29 September 2021

Revised: 28 November 2021

Accepted: 06 December 2021

Published: 22 December 2021

\begin{abstract}
Background: This study was designed to find the prevalence of anxiety and depression in school-going children with epilepsy. Methods: All the patients with epilepsy presenting during the study period underwent detailed clinical and EEG evaluation. Hospital Anxiety and Depression score (HADS) was used to screen for anxiety and depression. Results: We identified 190 patients with epilepsy during the study period. Out of these $30(15.8 \%)$ were diagnosed as having treatment resistance epilepsy. Anxiety was diagnosed in 114 $(60 \%)$ and depression in 62 (32.6\%). Patients with drug resistant epilepsy were found to have statistically significant markers in the form of higher scores for depression and anxiety, and lower IQ scores. Frequency of GTCS (Generaized Tonic Clonic Seizures) showed inverse correlation with IQ scores and direct correlation to the anxiety/depression scores. Conclusion: We conclude that anxiety and depression in school-going children with epilepsy is common and that it has a correlation with treatment resistance.
\end{abstract}

Keywords:- Depression in School, Epilepsy.

\section{INTRODUCTION}

Epilepsy is a common problem in childhood. Chronic childhood illnesses, including epilepsy, are known to be associated with anxiety as well as depression. The prevalence of anxiety and depression among children with epilepsy in different worldwide studies varied from $29 \%-62 \%$ and $23 \%-33 \%$ respectively.[1,2,3] Studies have also shown higher incidence of anxiety and depression in patients with treatment resistant epilepsy.[3] Oğuz et al reported that increased seizure frequency was associated with increases in anxiety and depression scores and Turky et al reported that poor seizure control predicted higher depression scores. $[4,5]$ The aim of this study was to evaluate the prevalence of depression and anxiety in school- going children with epilepsy and to assess whether it has any relationship to the severity of epilepsy and seizure control.

\section{MATERIAL AND METHODS}

This study was carried out from April 2019 to June 2020 at a tertiary referral center in the state of Kerala, in India. For the purpose of this study, all the patients above 6 years of age and below 18 years of age attending the hospital during this period with a provisional diagnosis of epilepsy were screened. Case definition of epilepsy was based on the published criteria of the Commission on Classification and 
Annals of International Medical and Dental Research

E-ISSN: 2395-2822 | P-ISSN: 2395-2814

Vol-8, Issue-1 | January-February 2022

DOI: 10.53339/aimdr.2022.8.1.13

Page no- 93-97 | Section- Research Article (Physiology)

Terminology of the international league against epilepsy (ILAE). After the initial identification, all the patients with seizures were evaluated for the presence of treatment resistance. Treatment resistance for the purpose of the study was defined as two or more seizures while on an optimal dose of a first-line agent with proper compliance. Patients with no seizures while on medication during the previous three years were considered to have good response to AED (Anti-Epileptic Drug). Patients were evaluated using a detailed clinical interview and examination. We obtained a detailed history including birth and perinatal history, developmental milestones, history of febrile seizures, CNS infection and trauma, and history of psychiatric problems from the patients and first degree relatives. Details of academic performance, a detailed family history and a history of any comorbidity were also obtained. Age at seizure onset was recorded for each type of seizures. Frequency of each seizure type was also noted. Features like the presence of any aura, the body parts involved, and the time of the day in which the seizures occurred. We specifically inquired about the precipitating factors for seizures like sleep deprivation, psychological stress, photic stimulation, and menses for each patient. The time to therapy was defined as the number of years from seizure onset to appropriate therapy. Details of AEDs tried and their maximum dose, response to treatment, and side effects were noted. Family history of seizures was determined.

All patients also underwent detailed neuropsychological and psychiatric evaluation. We used the Hospital Anxiety and Depression score (HADS) to assess anxiety and depression.
Mental functioning was assessed based on mental status examination, school performance (whether patient required special education) and intelligence quotient (IQ) scores. Verbal IQ and Performance IQ were assessed and Full scale IQ was calculated by using Wechsler Adult Intelligence Scale-III. All patients underwent one hour EEG recording including both asleep and awake record including the testing for any reflex components.

We compared the various clinical, electrophysiological and neuropsychological parameters of the study group. Student's t test was used for parametric variables, and MannWhitney test and Chi-Square test used for nonparametric variables. Spearman's correlation coefficient was used to assess the correlation between the number of seizures and various continuous variables. A $p$ value of $<0.05$ was considered significant. All the analyses were done with SPSS Statistics version 17 (Chicago, Illinois).

\section{RESULTS}

During the study period, 190 school-going children with seizure disorder attended the hospital [Table 1]. Mean age of the patients was $9.6 \pm 2.4$ years (range, 6 to 16 years). There were $102(53.6 \%)$ boys and 88 girls. After reviewing the records, $30(15.8 \%)$ patients were considered to have treatment resistant seizures. Among the 190 children in the study, anxiety was diagnosed in $114(60 \%)$ and depression in $62(32.6 \%)$. Patients with treatment resistance had higher incidence of anxiety $(28 / 30,93.3 \%)$ and depression (19/30, 63.3\%).

Patients in the treatment responsive group had higher IQ scores as compared to those in treatment resistant group [Table 2]. Mean scores for full-scale IQ $(p=0.026)$, verbal IQ 
Annals of International Medical and Dental Research

E-ISSN: 2395-2822 | P-ISSN: 2395-2814

Vol-8, Issue-1 | January-February 2022

DOI: 10.53339/aimdr.2022.8.1.13

Page no- 93-97 | Section- Research Article (Physiology)

$(p=0.038)$, and the performance IQ $(p=0.04)$ were significantly higher in the treatment responsive group. Spearman's correlation analysis comparing the IQ scores with the total number of GTCS in each patient showed an inverse correlation which was statistically significant for VIQ and FSIQ. The correlation coefficients were -0.309 and -0.331 respectively. Poor scholastic performance was present in 24 patients in treatment responsive group and 16 in treatment resistant group.
Similarly, both the mean anxiety scores and mean depression scores were higher in the treatment resistant group $(\mathrm{p}=0.03)$. Spearman's correlation analysis comparing the anxiety and depression scores with the total number of GTCS in each patient showed a direct correlation which was statistically significant [Table 3]. The correlation coefficients were 0.425 and 0.373 respectively.

Table 1: Age-wise distribution of patients

\begin{tabular}{|l|l|l|l|}
\hline Age & Number of children & Anxiety & Depression \\
\hline 6 to 9 yrs & 72 & 32 & 13 \\
\hline 10 to 12 yrs & 60 & 36 & 17 \\
\hline 13 to 16 yrs & 58 & 46 & 32 \\
\hline Total & 190 & 114 & 62 \\
\hline
\end{tabular}

Table 2: Comparison of IQ scores and anxiety/ depression scores between the two groups

\begin{tabular}{|l|l|l|l|}
\hline & $\begin{array}{l}\text { Treatment responsive epilepsy } \\
\text { Mean (SD) }\end{array}$ & $\begin{array}{l}\text { Treatment resistant epilepsy } \\
\text { Mean (SD) }\end{array}$ & P value \\
\hline Verbal IQ & $94.4(12.2)$ & $86.5(11.5)$ & 0.038 \\
\hline Performance IQ & $90.8(15.7)$ & $81.2(15.5)$ & 0.050 \\
\hline Full Scale IQ & $92.8(13.0)$ & $84.0(12.8)$ & 0.026 \\
\hline Anxiety score & $5.3(4.8)$ & $7.8(3.7)$ & 0.030 \\
\hline Depression score & $3.4(3.7)$ & $5.9(4.3)$ & 0.032 \\
\hline
\end{tabular}

IQ: Intelligence quotient; SD: standard deviation

Table 3: Spearman's correlation analysis between the total number of GTCS and other variables

\begin{tabular}{|l|l|l|}
\hline & Correlation coefficient & P value \\
\hline Verbal IQ & -0.309 & 0.041 \\
\hline Performance IQ & -0.277 & 0.068 \\
\hline Full Scale IQ & -0.331 & 0.028 \\
\hline Anxiety score & 0.425 & 0.004 \\
\hline Depression score & 0.373 & 0.013 \\
\hline Age of onset of seizures & 0.279 & 0.066 \\
\hline
\end{tabular}

GTCS: Generalized tonic-clonic seizures; IQ: Intelligence quotient 
Annals of International Medical and Dental Research

E-ISSN: 2395-2822 | P-ISSN: 2395-2814

Vol-8, Issue-1 | January-February 2022

DOI: 10.53339/aimdr.2022.8.1.13

Page no- 93-97 | Section- Research Article (Physiology)

\section{DISCUSSION}

Our results show that depression and anxiety are common in children with epilepsy. Moreover, depression and anxiety in these patients is much higher in those with uncontrolled epilepsy and higher seizure frequency. In a similar previous study, psychiatric problems especially personality problems were found to be more frequent in patients with treatment resistant epilepsy.[6] The possible relationship between epilepsy and psychiatric comorbidity could be due to the involvement of common brain areas in both conditions. Another confounding factor could be the adverse psychiatric effects associated with some anti-epileptic drugs. For example, levetiracetam is known to cause behavior problems in children.

We also found that patients with poor seizure control had lower verbal as well as performance IQ scores. Withstanding a direct cause effect relationship, it indicates that patients of epilepsy with relatively lower IQ scores are at a higher risk of poor seizure control. One practical difficulty that arises in this situation is the question of diagnosing psychiatric symptoms in children with intellectual disability. These children are likely to have significant impairments in their ability to express their emotional states.

A number of limitations need to be noted in interpreting the study findings. The sample size is relatively small, and there is a need for

\section{REFERENCES}

1. Ettinger $A B$, Weisbrot DM, Nolan EE, Gadow KD, Vitale SA, Andriola MR, et al. Symptoms of depression and anxiety in pediatric epilepsy further studies with larger sample sizes. We considered a relatively limited range of possible contributory factors to symptoms of depression and anxiety, and other factors such as parental well-being and other behavioral/psychiatric disorders would have been informative. We were not able to assess the contribution of individual AEDs to symptoms of depression and anxiety. We did not have a control group with which to compare the prevalence and nature of symptoms of anxiety and depression.

There is accumulating evidence that symptoms of both depression and anxiety in children with epilepsy can be successfully treated. A pilot study suggests that cognitive behavioral therapy (CBT) may be useful in treating children with epilepsy and social anxiety.[7] Psychoeducation programs for children with epilepsy and their parents should highlight the risks of both depression and anxiety in childhood epilepsy.

Our study highlights the need for regular screening of children with epilepsy for anxiety and depression, so that appropriate interventions can be instituted early.

\section{CONCLUSIONS}

All co-authors of this article were substantively involved in the study and/or the preparation of the article. No undisclosed groups or persons have had a primary role in the study and/or in preparation of the article. patients. Epilepsia. 1998;39(6):595-9. doi: 10.1111/j.1528-1157.1998.tb01427.x.

2. Alwash RH, Hussein MJ, Matloub FF. Symptoms of anxiety and depression among adolescents with seizures in Irbid, Northern Jordan. Seizure. 2000;9(6):412-6. doi: 10.1053/seiz.2000.0427. 
Annals of International Medical and Dental Research

E-ISSN: 2395-2822 | P-ISSN: 2395-2814

Vol-8, Issue-1 | January-February 2022

DOI: 10.53339/aimdr.2022.8.1.13

Page no- 93-97 | Section- Research Article (Physiology)

3. Dunn DW, Austin JK, Perkins SM. Prevalence of psychopathology in childhood epilepsy: categorical and dimensional measures. Dev Med Child Neurol. 2009;51(5):364-372. doi:10.1111/j.14698749.2008.03172.x

4. Oguz A, Kurul S, Dirik E. Relationship of epilepsyrelated factors to anxiety and depression scores in epileptic children. J Child Neurol. 2002;17(1):37-40. doi: $10.1177 / 088307380201700109$.

5. Turky A, Beavis JM, Thapar AK, Kerr MP. Psychopathology in children and adolescents with epilepsy: an investigation of predictive variables.
Epilepsy Behav. 2008;12(1):136-44. doi: 10.1016/j.yebeh.2007.08.003.

6. Regesta G, Tanganelli P. Clinical aspects and biological bases of drug-resistant epilepsies. Epilepsy Res. 1999;34(2-3):109-22. doi: 10.1016/s0920-1211(98)00106-5.

7. Jones JE, Blocher JB, Jackson DC, Sung C, Fujikawa $M$. Social anxiety and self-concept in children with epilepsy: a pilot intervention study. Seizure. 2014;23(9):780-5. doi: 10.1016/j.seizure.2014.06.011.

Source of Support: Nil, Conflict of Interest: None declared 